\title{
A força do "hábito alimentar": referências conceituais para o campo da Alimentaçáo e Nutrição
}

\section{| ${ }^{1}$ Juliana Klotz-Silva, ${ }^{2}$ Shirley Donizete Prado, ${ }^{3}$ Cristiane Marques Seixas |}

Resumo: Neste ensaio, buscamos problematizar a categoria hábito alimentar tal como vem sendo empregada no campo da Alimentação e Nutrição, quando se trata de propor soluçóes para agravos à saúde associados a práticas alimentares. $\mathrm{O}$ esforço de colocar em exame a ideia de hábito alimentar está ligado à intençâo de indicar suas (re) ligaçóes com outros campos da ciência. No campo alimentar-nutricional, hábito alimentar corresponde, predominantemente, ao que se come com regularidade. Como uma categoria empírica, desprovida de conceituação ou problematização epistemológica, corresponde a uma expressão do senso comum na academia, naturalizada, estudada a partir de procedimentos caraterísticos do Pensamento simplificador explicado por Edgar Morin e para a qual não se identifica questionamentos mais substantivos sobre seus sentidos e significados no contexto cultural, social ou psíquico. Entre muitas possibilidades a ser exploradas, indica-se seguir com Pierre Bourdieu através do conceito habitus, como já sugerido por alguns autores e realizado também por outros como uma das vias que podem enriquecer análises. Considera-se que, ao operar com conceitos que possibilitam ter em conta a complexidade (como concebida por Morin) que marca os hábitos alimentares, o próprio campo da Alimentação e Nutrição poderá seguir mais fortalecido e mais autônomo na sua lida científica.

> Palavras-chave: alimentação; hábito alimentar; habitus; complexidade.

\author{
1 Instituto de Nutrição, \\ Universidade do Estado do Rio \\ de Janeiro. Rio de Janeiro-RJ, \\ Brasil (juju_klotz@yahoo. \\ com.br). \\ ${ }^{2}$ Instituto de Nutrição, \\ Universidade do Estado do Rio \\ de Janeiro. Rio de Janeiro-RJ, \\ Brasil (shirley.donizete.prado@ \\ gmail.com). \\ ${ }^{3}$ Instituto de Nutrição, \\ Universidade do Estado do Rio \\ de Janeiro. Rio de Janeiro-RJ, \\ Brasil (levemente@uol.com.br).
}




\section{Introdução}

Neste ensaio, buscamos problematizar a ideia de hábito alimentar tal como vem sendo empregada no interior do campo da Alimentação e Nutrição no Brasil, quando se trata de propor soluçôes para agravos à saúde associados a práticas alimentares. ${ }^{1}$ Este esforço está ligado à indicação da importância do estabelecimento de (re)ligaçóes dessa categoria com outros campos da ciência, em particular, as Humanidades.

Consideramos que, no cenário atual, em que a obesidade vem sendo apresentada como pandemia em curso crescente, mudanças nos hábitos alimentares são preconizadas no âmbito da biomedicina de modo cada vez mais frequente e intenso. Argumentamos que tal proposição vem sendo formulada, predominantemente, no campo científico da Alimentação e Nutrição, desacompanhada, porém, de formulações teóricas, de fundamentos conceituais ou de interrogaçôes epistemológicas; trata-se dessa orientação biomédica ancorada no que Edgar Morin denomina paradigma simplificador. Entendemos que problemas alimentares como a obesidade são complexos e estáo a exigir abordagens que tenham em conta não apenas a diversidade disciplinar científica, mas ultrapassando-as, inclusive.

Nesse sentido, tratamos de exercitar uma aproximação inicial à categoria hábito, indicando que a trajetória de debates em torno dela é longa, ao mesmo tempo que nos coloca diante de reflexóes bastante elaboradas e sofisticadas. Tomando os modos de utilização da noção de hábito alimentar na produção de conhecimento no campo alimentar-nutricional e colocando-a em diálogo com conceitos das Ciências Humanas e Sociais, buscamos indicar a complexidade que marca a ideia de hábito.

Como uma via, entre outras, destacamos a construção de Pierre Bourdieu em torno do habitus como um caminho para a compreensão das relaçóes sociais mediadas pela comida.

\section{O hábito alimentar no campo Alimentação e Nutrição}

No campo alimentar-nutricional, mudar os hábitos alimentares dos indivíduos corresponde a um problema central, o que fica evidenciado, por exemplo, no documento recentemente publicado: o Guia alimentar para a população brasileira. O seu preâmbulo traz, logo no primeiro parágrafo, a seguinte assertiva: 
A Organização Mundial da Saúde (OMS) recomenda, por meio da Estratégia Global

para a Promoção da Alimentação Saudável, Atividade Física e Saúde, que os governos formulem e atualizem periodicamente diretrizes nacionais sobre alimentação e nutrição, levando em conta mudanças nos hábitos alimentares e nas condiçóes de saúde da população e o progresso do conhecimento científico. Essas diretrizes têm como propósito apoiar a educação alimentar e nutricional e subsidiar políticas e programas nacionais de alimentação e nutrição (BRASIL, 2014, p. 7, grifo nosso).

A posição da expressão (bem no meio) no texto é sustentada por todo o poder que representam, tanto organismos internacionais como a OMS (que a antecede), quanto a Ciência (que a sucede), concebida em seu sólido progresso. Ao mesmo tempo, os propósitos do documento conferem-lhe a grandiosidade da abrangência do País continental quando se propõe a "compreender um conjunto de estratégias que objetivam proporcionar aos indivíduos e coletividades a realização de práticas alimentares apropriadas [o que deve ser implementado] pelos gestores e profissionais do Sistema Único de Saúde em parceria com atores de outros setores, privilegiando a participação popular" (BRASIL, 2014, p. 8). E, para que não reste dúvida, "Este guia é para todos os brasileiros" (BRASIL, 2014, p. 11).

Ainda que o documento não estabeleça o que aí se entende por hábitos alimentares, seu sentido, certamente, está relacionado ao que consta do Glossário Temático: Alimentação e Nutrição, produzido e publicado no âmbito das mesmas instâncias do Ministério da Saúde (BRASIL, 2013).

Hábitos saudáveis, masc. pl. Conjunto de atos e atitudes que visam à manutenção da saúde e qualidade de vida. Nota: constituem hábitos saudáveis: a) alimentação adequada e balanceada; b) prática regular de atividade física; c) convivência social estimulante; d) busca, em qualquer fase da vida, de atividades ocupacionais prazerosas e de mecanismos de atenuação do estresse (BRASIL, 2013, p. 27).

Esse verbete remete a outro, a saber:

Práticas alimentares saudáveis, fem. pl. Usos, hábitos e costumes que definem padrôes de consumo alimentar de acordo com os conhecimentos científicos e técnicas de uma boa alimentação (BRASIL, 2013, p. 34).

Essa perspectiva é o que, em geral, encontramos em matéria de explanação do que se possa entender como hábitos alimentares no plano de documentos oficiais no campo alimentar-nutricional, cuja principal base científica que ancora tais construçôes - em linhas gerais, a mesma que sustenta a biomedicina na atualidade - corresponde a dados oriundos, principalmente, de estudos epidemiológicos 
voltados para a ingestão de nutrientes em face das necessidades biológicas do corpo humano (BOSI; PRADO, 2011; PRADO et al., 2011), como bem ilustram as palavras a seguir.

A avaliação da ingestão alimentar em populaçóes é uma medida cada vez mais presente em estudos epidemiológicos para a investigação da relação entre nutrição e doenças crônicas não transmissíveis já que as atuais recomendaçôes indicam a necessidade de se manter uma vida ativa com controle da ingestão alimentar. A medida da ingestão alimentar quantitativa é geralmente feita por meio de recordatório (ou diário) alimentar de $24 \mathrm{~h}$ ou por questionários semiquantitativos de freqüência alimentar (ANJOS et al., 2009, p. 151).

Depreendemos daí que a concepção de hábito alimentar que circula largamente no campo alimentar-nutricional restringe-se a um olhar que resulta em sua formulação como mera repetição frequente em certo período de tempo. Em outras palavras, entendemos que essa expressão vem sendo empregada no campo científico da Alimentação e Nutrição desacompanhada de questionamentos mais substantivos sobre seus sentidos analíticos e, com frequência, desprovida de contexto cultural, social ou psíquico. Consideramos, assim, que, nesse espaço da ciência, a ideia de hábito alimentar predomina de forma naturalizada, correspondendo apenas ao que as pessoas comem amiúde, como um padrão que se repete e para o que não há conceituação ou problematização de ordem epistemológica. Essa abordagem remete a um sentido de regras científico-nutricionais a ser seguidas permanentemente pelos indivíduos, conformando, assim, um caminho para formulação de proposições de solução de problemas como a obesidade.

Percebemos essa tônica como característica dos estudos de abordagem biomédica e nutricional que operam em base quantitativa, ancorados na mesma perspectiva das Ciências da Natureza. Dentro dos objetivos de identificação de regularidades universais, são tomadas as observaçôes de situações ou a experimentação em condiçôes controladas - reduzindo o biológico ao físico e o homem ao biológico -, em que predominam procedimentos nos quais os objetos são recortados e isolados, entendendo que suas causas e efeitos estão linearmente dados ao conhecimento por meio de processos lógicos de dedução ou indução (VASCONCELOS, 2007; BOSI et al., 2011; MORIN, 2011).

Nas palavras de Edgar Morin (2011, p. 11, grifos do autor): "Vivemos sob o império dos princípios de disjunção, de redução e de abstração, cujo conjunto constitui o que chamo de o 'paradigma de simplificação'”. No rastro da separação 
entre sujeito pensante e objeto de estudo e da verdade estabelecida a partir

de ideias tidas de per si como claras e distintas, intensifica-se a especialização a "despedaçar e fragmentar o tecido complexo das realidades e [a] fazer crer que o corte arbitrário operado no real era o próprio real” (MORIN, 2011, p. 12). Controlando o pensamento científico ocidental desde Descartes, esse princípio gerou tanto o isolamento radical entre a Física, a Biologia e as Ciências Humanas, quanto importantes desenvolvimentos tecnológicos, e contando com contexto histórico propício, articula-se na atualidade com graves ameaças à humanidade "ligadas ao progresso cego e incontrolado do conhecimento (armas termonucleares, manipulaçóes de todo tipo, desagregamento ecológico, etc.)" (MORIN, 2011, p. 9).

Em face daquilo que o paradigma simplificador não dá conta, Morin propõe o pensamento complexo, este que exige esforços de aproximação ao que é tecido junto e do estabelecimento de (re) ligaçôes entre diversos campos do conhecimento científico, transbordando-os necessariamente - ou seja, buscando ultrapassar o âmbito da Ciência e alcançar outros espaços de inserção dos problemas no mundo. Nesse movimento dialógico, Morin (2011) considera que ambiguidade e contradiçãa, ordem e desordem, conjunção do uno e dos múltiplos participam dos fenômenos sociais, entre os quais está a alimentação.

A partir dessa perspectiva, compreender práticas alimentares e corporais e suas implicaçôes sobre a saúde como questôes na contemporaneidade significa estabelecer como problemas: a fome, a desnutrição, a obesidade, a anorexia, a bulimia, as compulsóes alimentares e corporais, para citar alguns exemplos no âmbito de interesses deste ensaio. Tais empreendimentos, necessariamente, demandam considerar, além da Ciência e sua pluralidade epistêmica, desde a subjetividade, os afetos, os sentimentos íntimos, as práticas e os saberes construídos na vida cotidiana, a distribuição de poder e de riquezas, as macroestruturas, os estados, as naçôes, as corporações transnacionais, até o futuro do planeta. Significa a necessidade de termos em conta a dinâmica das sociedades, hoje cada vez mais estáveis na instabilidade, homogêneas e distintas, (des)informadas, (des)iguais, recusando e desejando, simultaneamente, essa vida que coloca a redução contínua da condição humana no lugar de consumidor e de mercadoria no grande mercado local e global das matérias e dos símbolos. Se tomar os problemas alimentares em sua complexidade inclui a Ciência - seja 
no plano do paradigma simplificador ou do pensamento complexo -, é necessário trabalhar com teorias e conceitos, interrogando-os epistemologicamente, tanto quanto problematizar o senso comum. Náo se trata de hierarquizar ciência e senso comum, separando-os como o que tem ou não valor, o que é verdadeiro ou falso, mas tomando-os como partícipes da complexidade da vida, uma vez que ambos constroem e se constroem em meio a contradiçóes, incertezas "no tecido de acontecimentos, ações, interaçôes, retroações, determinaçóes, acasos, que constituem nosso mundo fenomênico" (MORIN, 2011, p. 13).

Trata-se de conferir maior precisão analítica às palavras ou expressóes utilizadas nos esforços de aproximação científica ao que está em estudo, de atentar para a frequente naturalização de fenômenos (como a alimentação) e das palavras ou expressóes (como hábito alimentar) que os traduzem, evitando operar num plano correspondente ao do senso comum travestido de conceito científico - ou do uso de categorias empíricas como se analíticas fossem. É nesse sentido que Minayo (2010, p. 179) aborda a diferença entre categorias empíricas como expressóes do senso comum, "que os atores sociais de determinada realidade constroem e lhes permitem dar sentido a sua vida, suas relaçôes e suas aspiraçôes. Portanto, emanam da realidade", e categorias analíticas, próprias da abordagem científica, que "retêm, historicamente, as relaçôes sociais fundamentais, servindo como guias teóricos e balizas para o conhecimento de um objeto" (MINAYO, 2010, p. 178).

Nesses estudos de caráter simplificador que predominam no campo nutricional, palavras diferentes são usadas como sinônimos. Assim se dá com a expressão hábito alimentar, usada de modo a obnubilar sua percepção como elemento estruturante das análises, como ordenadora de um modo de comer que o reifica. Naturalizada, segue substituída, ao longo dos parágrafos, por outras expressóes igualmente tidas como coisa dada e clara para todos, com a mera finalidade de evitar repetição de palavras em trechos próximos: "consumo alimentar", "cultura alimentar", "padrão alimentar", "comportamento alimentar", "ingestão alimentar" são iguais. Simples assim. Em síntese, o que essas expressôes significam: ingestão de nutrientes. A redução de significado de palavras como "consumo" e sua equivalência à "ingestão alimentar" pode ser notada em textos do campo nutricional como já apontaram Bosi et al. (2011). Ao fim e ao cabo, fenômenos alimentares da ordem do social, do cultural ou do psíquico, como consumo, cultura ou comportamento, passam à condição de alimentos reduzidos 
a uma só função: a de carreadores de nutrientes, que, por sua vez, são ingeridos

atendendo ou não a necessidades celulares cientificamente estabelecidas. $\mathrm{O}$ trecho abaixo ilustra essa perspectiva, como representante do conjunto de estudos e textos científicos em exame.

\begin{abstract}
No que se refere aos hábitos alimentares, a ingestão de frutas e hortaliças é realizada por $36,7 \%$ e $63,3 \%$ dos participantes ao menos uma vez ao dia, respectivamente. Estes achados merecem atenção, visto que a recomendação de frutas e hortaliças é de três porçôes diárias/cada, e que o consumo adequado desses alimentos configura um fator protetor contra o desenvolvimento de DCNT [Doenças Crônicas Não Transmissíveis], pois são fontes de fibras e compostos bioativos, que possuem atividades antioxidantes no organismo (SILVA et al., 2014, p. 1.415, grifos nossos).
\end{abstract}

Observa-se, por exemplo, que "consumo" é conceito debatido no campo das Humanidades por meio de vasta produção científica, que busca compreender seu alcance na sociedade contemporânea. $\mathrm{O}$ mundo do consumo oferece modos de viver, necessidades e desejos, sonhos, afetos, excessos e carências, vazios a ser permanentemente preenchidos; coloca à disposição das pessoas produtos que representam a inserção na sociedade, que as identificam como seres humanos ou meros consumidores; constrói discursos e práticas em relaçôes ao mesmo tempo consensuais e conflituosas, caóticas e organizadoras; orienta a distribuição de capitais materiais e simbólicos, fluxos econômicos locais e globais, relacionandose com a produçáo e conformando o processo de construção da sociedade em que todos vivem. Ao consumir - comprando, desejando, imitando, negando... -, todos constroem e consomem a sociedade, as suas identidades, subjetividades, seus modos de Ser (BAUMAN, 2008; GIDDENS, 2002; BOURDIEU, 2011a). Se as pessoas são o que comem, vale também dizer que comem o que são (GRACIAARNAIZ, 2015). Reduzir o consumo de comida - mediadora de relaçôes sociais - à aquisição de alimentos ou à ingestão de nutrientes é o mesmo que limitar a possibilidade de compreensão das relações sociais nas quais a alimentação se dá em sua complexidade (BOSI et al., 2011), o que exige considerar ordenamentos sociais, distribuição de poder, contradiçôes, paradoxos, história, contexto, interesses políticos, econômicos, ideologias, valores, pulsóes...

Carvalho (2012) chama a atenção, por exemplo, para a existência de muitas publicações do campo Alimentação e Nutrição que tratam hábito alimentar como equivalente a comportamento alimentar e fala sobre o achatamento a que estes termos são submetidos - o que também é descrito por Fischler (1995) -, 
1072 limitando oportunidades de análises e detalhamentos sobre modos de se adequar às regras nutricionais e de incorporá-las, reproduzindo-as sem reflexão mais aprofundada. Nessa mesma linha, Klotz-Silva, Prado e Seixas problematizam a categoria comportamento alimentar entendida no campo da Alimentaçáo e Nutrição, predominantemente, como evento controlável e cuja repetição conduz à alteração do hábito, problematizando-a.

$\mathrm{Na}$ perspectiva do pensamento complexo, o comportamento se desloca de ação condicionada para uma extensão que comporta as dimensōes sociocultural, subjetiva e individual, consciente e inconsciente, enquanto o hábito se afirma como aquilo que na repetição faz sentido para o indivíduo, permitindo que este possa apropriar-se de forma singular das informaçóes e orientaçóes provenientes da ciência e sustentar suas mudanças (2016, p. 1.103).

Tal como hábito alimentar e seus "sinônimos", outras expressóes circulam como palavras dadas, que falam por si mesmas, de tão naturalizadas que estão no campo cientifico da Nutrição. E, assim, seguem nos livros, artigos e documentos vários como categorias empíricas; é o caso de "população", que aparece como se "sociedade" fora; "individuo" tomado por "pessoa"; "saúde pública" por "saúde coletiva"; "sexo" por "gênero"; "cultura" por "regionalismo", "cultura alimentar" por "culinária regional”... Enfim, uma miríade de palavras cujo alcance, como base científica, é limitado por não dispor dos recursos próprios das categorias analíticas, dos conceitos, das teorias, com implicações também no que concerne às açôes ou intervençôes a que se propõem.

Contudo, consideramos relevante ressalvar a pluralidade de significados em torno de cada uma dessas palavras quando tomadas em contextos diversos. Conforme a perspectiva teórica que subjaz a cada texto (assumida, reconhecida ou sequer percebida por seus autores), o entendimento a respeito dessas categorias pode se apresentar mais restrito, reduzido ou ampliado. Assim, tanto nas expressōes acima assinaladas, como em outras, olhares mais simplificados ou complexos podem estar presentes, de acordo com o ponto de partida analítico adotado.

No âmbito da pesquisa qualitativa sobre alimentação há um conjunto de trabalhos que estabelecem criativo e inovador diálogo com diversos campos das Humanidades. Nesses estudos, em investimentos de fôlego, autores clássicos e contemporâneos são visitados e revisitados, a partir dos quais sólidas análises são empreendidas a partir de teorias, conceitos e tomando categorias analíticas como 
ferramentas bem definidas, potentes no sentido de estabelecer diálogo profícuo com categorias empíricas que circulam em campos diversos, incluindo o científico.

A título de exemplo, há trabalhos que utilizam categorias de análise, como ingerir, alimentar e nutrir, tomadas como conceitos centrais na delimitação do próprio campo da Alimentação e Nutrição, enquanto domínio científico (CARVALHO ; LUZ; PRADO, 2011; PRADO et al., 2011) ou hábito alimentar regional (PAIVA, 2011; PAIVA ; FREITAS; SANTOS, 2012) ou, ainda, distinguindo hábitos de comportamentos alimentares para criticar como estes termos vêm sendo naturalizados no campo (CARVALHO, 2012; KLOTZSILVA; PRADO; SEIXAS, 2016).

Críticas importantes permanecem, no entanto, dirigidas a outra parcela desses estudos qualitativos correspondentes à necessidade de seu aprofunda mento teórico, de modo a superar questôes similares àquelas identificadas nos trabalhos construídos em bases quantitativas e de caráter biomédico: aqui também estão presentes insuficiências conceituais e o frequente uso do senso comum no que é apresentado como análise científica, não indo além dos dicionários básicos da linguagem cotidiana na delimitação do alcance de palavras centrais, quando muito (CANESQUI, 2009; KLOTZ-SILVA et al., 2010; KLOTZ-SILVA, 2011).

Enfim, na maior parte dos estudos e documentos produzidos no campo alimentar-nutricional, hábito alimentar aparece como categoria empírica, comportando o reduzido significado de ingestão repetida e frequente de nutrientes. Diante dessas abordagens em que a insuficiência conceitual dá o tom das discussóes e das proposiçóes de intervenção, passamos a colocar em exame a ideia de hábito alimentar de modo a identificar, como em Morin, (re)ligaçôes dessa categoria com outros campos da ciência, em particular, as Humanidades.

Ressalvamos que se trata de um primeiro passo no necessário processo que, como demonstramos acima, envolve muitos autores em diferentes correntes de pensamento a lidar com a ideia de hábito. A opção por trazer o conceito de habitus formulado por Pierre Bourdieu parece-nos interessante e segue os caminhos traçados por alguns estudiosos que vêm trabalhando nessa linha, abrindo caminhos para seu aprofundamento (GOÉS, 2008; PACHECO, 2008; PAIVA, 2011; FREITAS et al., 2011; CARVALHO, 2012; SETTON, 2013). 
Alguns debates sobre o hábito e o conceito "habitus" em Pierre Bourdieu

Para uma delimitação inicial da amplitude do esforço necessário à abordagem da ideia de hábito, uma consulta ao Dicionário de Filosofia, de José Ferrater Mora (1978), revela dezenas de mençóes a essa expressão, envolvendo debates que se estendem por séculos, passando por muitos estudiosos que, em diversas correntes de pensamento, tratam: da Natureza e do Espírito; da necessidade e da liberdade; dos reflexos; do respeito e da proporção; das virtudes, da prudência e da razão e de mais um importante conjunto de outros signos desconhecidos ou tidos como distantes da visão de mundo hegemônica na ciência nutricional.

O mesmo se dá em Nicola Abbagnano (2007) e onde também é possível diferenciar dois verbetes: hábito/costume e hábito/disposição. Já em Aristóteles, hábito aparece com esses sentidos distintos, seja o de qualidade ou o modo como alguém tem uma coisa ou característica como uma possessão permanente, seja o de predicamento expressando uma disposição do ente de caráter acidental ou transitório (MORA, 1978). Pacheco (2008) também utiliza Abbagnano para abordar hábito como costume e hábito como disposição.

O hábito como costume guarda correspondência com a repetiçáo de acontecimentos ou comportamentos em decorrência de algum mecanismo de ordem física, fisiológica, biológica ou social por meio do exercício aprendido e guardando tal similaridade entre si que permite certa previsibilidade para o futuro. Pascal, discutindo o papel do hábito na crença, dizia que "É o costume (coutumé) que torna as nossas provas mais sólidas e dignas de crédito: ele redobra o automatismo, que arrasta o intelecto sem que este se aperceba" (PENSÉES, ${ }^{\circ}$ 252 apud ABBAGNANO, 2007, p. 494). Nessa esteira, David Hume explica conexôes causais a partir do hábito entendendo que o costume de ver fatos juntos possibilita a previsão de um quando o outro se coloca (ABBAGNANO, 2007).

Henry Bergson é um estudioso que busca na noção de hábito bases para a abordagem das obrigaçóes morais, não como elementos da razão, mas como costumes que asseguram a vida e a solidez do corpo social, o que aparece também em Maine de Biran, Georg Hegel, entre outros, na Filosofia contemporânea, especialmente, em leituras identificadas como idealistas e espiritualistas (ABBAGNANO, 2007). 
É comum que hábito/costume, em sua repetição fácil ou confortável por corresponder a mecanismo rotineiro, seja confundido com o hábito como disposição constante ou relativamente frequente para proceder de certa maneira, implicando uma espécie de compromisso exigente de esforço para ser realizado. No dizer aristotélico, saúde e virtude constituem hábito ou a disposição para, por exemplo, enfrentar tendências e impulsos como a ira, a cupidez, o medo, ou para alcançar alguma moderação nesses ímpetos. Virtude e prudência estão presentes nessas reflexôes sobre hábito contextualizado naquela sociedade, naquele tempo, o que reitera a possibilidade de religação com a Filosofia, desde seus primórdios (ABBAGNANO, 2007).

O habitus aparece como versão latina desse elemento do pensamento aristotélico em Tomás de Aquino (WACQUANT, 2007). Para ele, o habitus relaciona-se à prudência e à virtude, importantes para enfrentar e controlar emoçóes e impulsos, acarretando açôes, que são aprendidas, duram e são difíceis de remover (ABBAGNANO, 2007; MORA, 1978). Construção dessa ordem é retomada em Émile Durkheim (1995), correspondendo a disposiçôes aprendidas na infância através dos processos de socialização e educação ou, "para designar um estado geral dos indivíduos, estado interior e profundo, que orienta suas açôes de forma durável" (SETTON, 2002, p. 61). Aqui, a marca central reside na ideia de um habitus que opera no sentido da reprodução da sociedade, preocupação que orienta a obra durkheimiana.

Marcel Mauss (1974), em seus estudos sobre o corpo, toma o habitus como técnica e também como elaboração da razão prática coletiva e individual, colocando em cena sua fonte na sociedade e variando conforme lugares e tempos. Encontra-se na obra de Max Weber (1967), quando aborda o ascetismo religioso e suas relaçooes com a constituição do capitalismo, como também em Norbert Elias (1990), ao tratar do habitus emocional das pessoas no mundo civilizado (WACQUANT, 2007); em ambos estão presentes profundos questionamentos acerca de determinismos lineares sobre os "hábitos".

Gilles Deleuze (2006) trata do hábito em discussôes inovadoras sobre o tempo, lidando com ideias de frequência e repetição, trazendo a dinâmica do tempo com rupturas, como fala Gualandi (2003). Ele considera que, segundo o pensamento deleuziano, hábito corresponde a "uma disposiçáo de expectativa com relação a alguma coisa que se repete. Um hábito é um presente vivo que contrai do passado e antecipa o futuro" (GUALANDI, 2003, p. 71). 
Nesta primeira e breve mirada a apenas dois dicionários mais específicos do campo das Humanidades já se pode identificar um complexo percurso de debates transcorrendo ao longo de séculos que não pode ser ignorado. Outros autores inseridos em distintos campos de produção de conhecimentos e saberes poderiam ser mencionados, bem como apresentados os aprofundamentos de suas contribuiçôes; contudo, o que se propôe até aqui é, tão somente, ressaltar a significativa amplitude dos esforços a ser considerados quando se busca aproximação às reflexôes sobre hábito ao longo dos tempos e em diferentes campos do conhecimento.

Nesse sentido, tomamos aqui as contribuiçôes de Pierre Bourdieu, um desses pensadores cujos densos aportes teóricos vêm sendo debatidos e tomados como fundamento para inúmeros estudos mundo afora e que trata do conceito de habitus (2009, 2011a, 2011b, 2011c) inclusive no campo da Alimentação e Nutrição.

Para Loïc Wacquant, é nesse autor em que se encontra importante "renovação sociológica do conceito delineado para transcender a oposição entre objectivismo e subjectivismo" (2007, p. 65-66). Estudar os espaços sociais (desde pequenas formaçôes locais até os ordenamentos construídos entre humanos e suas relaçôes sociais no mundo) em que as pessoas passam fome e/ou que engordam além dos limites estabelecidos pela biomedicina exige transcender a abordagem linear e reducionista que tem olhos para "dados objetivos" relativos a balanço energético dos indivíduos matematicamente registrados através de ingestão de nutrientes e de medidas corporais e que descarta como "erros" aquilo que traz a marca da subjetividade. Mais que indivíduos (no sentido naturalizado de unidade corporal biológica) que ingerem mais ou menos energia do que o quantum gasto em atividade física, trata-se, aqui, de compreender pessoas ou coletividades - agentes - em relaçóes sociais mediadas pela "comida", naquilo que há de permanência e/ ou de mudança.

Nesse processo, Bourdieu (2004a) destaca que as características objetivas e as subjetivas estáo presentes, principalmente, nas interpretaçóes que os cientistas fazem dos sujeitos: é necessário observar suas objetividades e ressaltar as subjetividades das relaçóes e interaçóes sociais. Agentes lidam com a comida de modo dinâmico, incorporando, rejeitando e interligando normas de ordem biomédica e/ou de outras esferas e valores sociais - ora uns, ora outros, ou vários, simultaneamente. De acordo com o campo em que se inserem, esses 
agentes podem comer este ou aquele prato, preparação, petisco, belisco, buscando

capitalizar material e simbolicamente conforme disposiçóes estruturadas e, assim, estruturando e (re)orientando a vida.

Pensando, agindo e sentindo de modos específicos em cada situação e no conjunto delas, definem o que comer, onde comer, como comer... por meio de disposiçóes duráveis ou de capacidades aprendidas ao longo da vida que as orientam na construção de respostas em face das demandas e das limitaçóes próprias dos espaços sociais em que se inserem (WACQUANT, 2007). A comida assume expressôes distintas em cada situação, momento histórico ou grupo social, podendo as mesmas práticas alimentares e corporais ser mais ou menos valorizadas ou carrear distinçôes específicas de acordo com o contexto considerado.

Por meio da produção e do consumo de alimentos, sempre simbolizados, pessoas e sociedades julgam e são julgadas por si mesmas e pelo outro, e nessas práticas materializam-se também valores sobre si e sobre outrem. Gordura ou magreza são tratadas como beleza, força, fragilidade, delicadeza, feiura, fraqueza em diferentes circunstâncias e períodos históricos; são fenômenos sociais distintos em conformidade e conformadoras dos habitus dos agentes no contexto. Por esses caminhos, reitera-se a recusa à dualidade objetividade-subjetividade, que se articula por meio do habitus entendido como um "sistema das disposiçóes socialmente constituídas que, enquanto estruturadas e estruturantes, constituem o princípio gerador e unificador do conjunto das práticas e das ideologias características de um grupo de agentes” (BOURDIEU, 2011b, p. 191).

Nas palavras de Wacquant, o "habitus é uma noção mediadora que ajuda a romper com a dualidade de senso comum entre indivíduo e sociedade ao captar 'a interiorização da exterioridade e a exteriorização da interioridade'” (2007, p. 65-66, grifo do autor). O habitus pode ser relacionado às várias regras e condições sociais que todos constroem e absorvem, como as estruturas e relaçóes sociais, que também constroem e atuam na vida dos sujeitos, que da mesma forma as constroem a todo o momento (ORTIZ, 1983). Para além da prescrição das normas nutricionais e corporais dirigidas aos indivíduos, o habitus possibilita ter em conta elementos e movimentos no sentido de reprodução social presentes nesse processo. Trata-se, assim, de considerar a construção e reconstrução de hábitos alimentares nos mundos interno e externo de cada indivíduo, comportando aspectos singulares e não generalizáveis. Se a universalidade das orientaçóes 
nutricionais visa a uma saúde preconizada pelos parâmetros da biomedicina, é preciso observar que é no plano individual que o hábito alimentar se expressa, sendo ao mesmo tempo a manifestação de um habitus que não se universaliza e comporta uma interioridade-externa e uma exterioridade-interna que não podem ser fragmentadas em dois polos opostos.

$\mathrm{Na}$ diversidade dos agentes, estes que são marcados pela distinção ou por seus “sistemas de diferenças" (BOURDIEU, 2011a, p. 240), opera também o habitus. Bourdieu (2011a) exemplifica itens e procedimentos através dos quais as classes mais abastadas procuram se distinguir das que lhes são subalternas: vestimentas, artigos pessoais, alimentação etc. A diferenciação na acumulação de capitais materiais (financeiro ou econômico) e simbólicos (como as comidas de rico e de pobre, estudadas por Canesqui, em 1976) está relacionada às distinções entre as classes, caracterizando os seus habitus individuais e na estrutura social. Ao trazer para a cena as classes sociais nas quais os agentes estão inseridos, o autor coloca a possibilidade de análise da fome e da obesidade também como fontes de interesses de classes sociais dirigidos à acumulação de capitais materiais e simbólicos.

Tais práticas e ideologias poderão atualizar-se em ocasióes mais ou menos favoráveis que lhes propiciam uma posiçâo e uma trajetória determinadas no interior de um campo intelectual que, por sua vez, ocupa uma posição determinada na estrutura da classe dominante (BOURDIEU, 2011b, p. 191).

Nas regras sociais relativas à comida e ao corpo, os agentes são construídos e constroem a sociedade. Não se trata apenas de entes, mas, sim, da construçáo social num tempo e num espaço em meio a relaçóes de poder, no interior de classes sociais. Sujeitos ativos operando e jogando entre interesses diversos, buscando capitalizar-se econômica e simbolicamente em cada situação. Comer isso ou aquilo, neste ou naquele momento, em tal ou qual situação pode representar de ganhos importantes a perdas definitivas de capital no jogo e no contexto da vida, mobilizando objetivos que mudam a cada cenário.

A partir do habitus, como no conceito bourdiesiano, pode-se lidar com os hábitos alimentares percebendo-os de modo mais complexo, superando reducionismos que hoje são característicos nos estudos implementados no campo alimentar-nutricional e (re)ligando-os dialogicamente, a conceitos e teorias situados em outros campos e além deles. Pode-se, assim, considerar outros aspectos (econômicos, políticos, sociais, culturais) em questôes relativas 
à alimentação, corpo, saúde e naquilo que há de reprodução e de transformação social nas práticas e nas teorias mobilizadas em face dos problemas construídos.

A interligação entre conceitos na abordagem bourdiesiana impóe a necessidade de discutir o campo da Alimentação e Nutrição, espaço social onde a categoria empírica hábitos alimentares guarda centralidade, construindo-o e por ele sendo (re)construída. Nesse movimento, é possível considerar e construir uma nova compreensão para ambos, a categoria e o campo. Para Bourdieu, o campo equivale a um "microcosmo" no qual têm lugar acordos, lutas, forças, conflitos, tensóes e interesses: "o limite de um campo é o limite dos seus efeitos ou, em outro sentido, um agente ou uma instituição faz parte de um campo na medida em que nele sofre efeitos ou que nele os produz" (2004b; 2011c, p. 31).

No mundo contemporâneo, marcado pela fragmentação das identidades, pelo esgarçamento das tradiçóes, pelo individualismo levado a extremos e onde imperam os interesses de mercado no sentido da acumulaçáo de capital, sujeitos sociais e agentes individuais e coletivos movimentam-se nos campos conforme interesses em jogo. A luta concorrencial se expressa cotidianamente das formas mais sutis e avassaladoras, podendo resultar em conservaçôes da situação do campo ou na sua transformação (BOURDIEU, 1983, 2004b, 2011a). Tais jogos concorrenciais e disposiçôes para diferenciações também estão presentes na ciência e, em particular, na Alimentação e Nutrição, guardadas as especificidades de cada um desses campos.

Aqui, o habitus dos agentes científicos envolve a lida com correntes de pensamento, teorias, conceitos, categorias analíticas e empíricas. Interesses (in) conscientes em denegar a complexidade do habitus e da a limentação estáo presentes nos jogos concorrenciais que se dáo no campo científico, principalmente, em textos construídos a partir de olhares simplificadores, hegemônicos na produção de conhecimento científico que impera na contemporaneidade.

Regras acadêmicas que estabelecem validade apenas para o que é publicado, por exemplo, nos últimos três ou cinco anos e em periódicos internacionais indexados em bases prestigiosas no mundo das ciências naturais e da ciênciamercadoria fazem valer revisōes de literatura que não alcançam os clássicos, tampouco os debates conceituais que atravessam séculos sobre os hábitos e que importam na problematização dos hábitos alimentares. É o que se observa, por exemplo, no artigo de Vaz e Benneman (2014), que, na tentativa de estabelecer 
diferenças entre comportamentos e hábitos alimentares, acaba por realizar uma compilação de ideias fruto de revisão bibliográfica sem que se promova o diálogo entre as mesmas, resultando em conclusôes óbvias e deterministas de caráter quantitativo e prescritivo.

Assim, a ideia de hábito alimentar como mera repetição ou ingestão de nutrientes é reiterada e corroborada cotidianamente por estudos que não interrogam o hábito em sua amplitude conceitual. Ao associarmos os conceitos bourdiesianos de habitus, distinção e campo, podemos compor um mosaico que nos permite complexificar o problema. Ou seja, não se trata de simplificar o problema dos hábitos alimentares em benefício de uma orientação universalizante de mudança que garanta uma vida saudável. Trata-se, igualmente, de complexificá-la inserindo-a no campo de disputas concorrenciais que lhe é pertinente.

Bourdieu (2006) denuncia a hipocrisia própria a determinados campos científicos. Por meio da sua ideia de denegação, constrói-se a dissimulação em que alguns interesses podem não transparecer tão facilmente. Desse modo, autores podem se apropriar dos conceitos e explicaçóes conforme as suas necessidades e objetivos. Aqueles que não mencionam ou não reconhecem essa complexidade se envolvem em um jogo político escondido pelo debate apoiado no senso comum, o que contribui para que os discursos sobre os hábitos alimentares continuem no plano simplificador do senso comum.

São preocupantes os rumos reducionistas que se acentuam no campo da Alimentação e Nutrição quando se nota que hoje predomina esse olhar para a obesidade, que a trata como fenômeno individual, fixando-se na prescrição do que é tido como controlável - a alimentação e a atividade física - como formas objetivas de resolver o problema. Também trazem preocupaçôes as movimentações no campo científico da Alimentação e Nutrição que firmam como referências fundamentais para a produção de conhecimentos os valores das ciências da Natureza em detrimento daqueles característicos das Humanidades. Considera-se a necessidade de pensar, simultaneamente, os problemas relativos à alimentação que se instauram na sociedade e os caminhos trilhados no âmbito do campo científico da Alimentação e Nutrição - com vistas ao seu enfrentamento. Entende-se que, ao trazer para o cenário o paradigma da complexidade para a análise dos problemas e das soluçóes propostas, há chances de investir na ampliação e no aprofundamento de tais análises, problematizando-as de um 
ponto de vista epistemológico e buscando trazer à luz os interesses em jogo no âmbito da ciência e da sociedade.

\section{Notas finais}

Se os hábitos alimentares encontram-se no foco da cena e se sua abordagem está colocada no âmbito da ciência, é possível dizer de sua força nos dias atuais. Para discutir a força dos hábitos alimentares, é imprescindível que teorias, conceitos e categorias analíticas sejam mobilizados, principalmente, aqueles oriundos dos campos do conhecimento situados nas Humanidades. No campo científico da Alimentação e Nutrição, seus objetos de estudo são apresentados sob a insígnia do biopsicossocial, o que, de per si, demanda visitas habituais a diferentes campos do conhecimento (Ciências Biológicas e Humanidades) e a seus correspondentes fundamentos teóricos e metodológicos, num reconhecimento de distintos referenciais epistêmicos e das diferentes culturas científicas existentes. Isso significa valorizar a ciência e seu efetivo potencial de construir, sejam explicaçôes para acontecimentos da ordem da Natureza, sejam compreensóes de fenômenos da esfera da Sociedade (DILTHEY, 1956), como é o caso da Nutrição e da Alimentação, respectivamente, na sociedade contemporânea.

A complexidade dos fenômenos, como concebida por Morin (2011), ressalta a necessidade de (re)ligaçóes entre campos da ciência e de seu próprio transbordamento para outros espaços da vida em sociedade. Pensar os objetos do campo alimentar-nutricional para além do modelo simplificador, como na biomedicina, significa a construção de esforços para identificação de autores e correntes de pensamento que possam subsidiar as análises de fenômenos como a fome ou a obesidade ou os chamados transtornos alimentares no mundo.

Bourdieu, através do conceito de habitus, oferece ricas possibilidades para a compreensão das pessoas que vivenciam essas situaçôes, assim como para os pesquisadores que estudam essas temáticas. Seus investimentos teóricos - como a crítica a dualidades que perduram no pensamento simplificador (objetivo/ subjetivo ou indivíduo/sociedade) ou a consideração de distinções de classe social, entre outros - guardam importante potencial em análises que ainda estão por ser realizadas. Operando com conceitos que permitem considerar complexidades, acreditamos que o próprio campo da Alimentação e Nutrição poderá seguir mais fortalecido e com mais autonomia na sua lida científica e prática. ${ }^{2}$ 


\section{Referências}

ABBAGNANO, N. Dicionário de Filosofia. 5. ed. São Paulo: Martins Fontes, 2007.

ANJOS, L. A; SOUZA, D. R.; ROSSATO, S. L. Desafios na medição quantitativa da ingestão alimentar em estudos populacionais. Revista de Nutrição, v. 22, n. 1, p. 151-161, 2009.

BAUMAN, Z. Vida para consumo: a transformação das pessoas em mercadoria. Rio de Janeiro: Jorge Zahar, 2008.

BOSI, M. L. M. et al. O enfoque qualitativo na avaliação do consumo alimentar: fundamentos, aplicaçôes e consideraçôes operacionais. Physis: Revista de Saúde Coletiva. Rio de Janeiro, v. 21, n. 4, p. 1.287-1.296, 2011.

BOSI, M. L. M.; PRADO, S.D. Alimentação e Nutrição em Saúde Coletiva: constituição, contornos e estatuto científico. Ciência e Saúde Coletiva. Rio de Janeiro, v. 16, n. 1, p. 7-17, 2011.

BOURDIEU, P. A distinção: crítica social do julgamento. 2. ed. Porto Alegre: Zouk, 2011a. . A economia das trocas simbólicas. 7. ed. São Paulo: Perspectiva, 2011 b.

. A produção da crença: contribuição para uma economia dos bens simbólicos. 3. ed. Porto Alegre: Zouk, 2006.

- Algumas propriedades dos campos. In:

Questôes de sociologia. Rio de Janeiro: Marco Zero, 1983, p. 89-94.

- Espaço social e poder simbólico. In: . Coisas ditas. São Paulo: Brasiliense, 2004a, p. 149-168.

. O poder simbólico. 15. ed. Rio de Janeiro: Bertrand Brasil, 2011c.

. O senso prático. Rio de Janeiro: Vozes, 2009.

. Os usos sociais da ciência: por uma sociologia clínica do campo científico. São Paulo:

UNESP, $2004 \mathrm{~b}$.

BRASIL. Ministério da Saúde. Secretaria-Executiva. Glossário temático: alimentação e nutrição. 2. ed. Brasília: Ministério da Saúde, 2013. 52 p. Disponível em: <http://bvsms. saude.gov.br/bvs/publicacoes/glossario_tematico_alimentacao_nutricao_2ed.pdf>. Acesso em: 18 abr. 2015.

- Secretaria de Atenção à Saúde. Departamento de Atenção Básica. Guia alimentar para a população brasileira. 2. ed. Brasília: Ministério da Saúde, 2014. 156 p. Disponível em: <http://189.28.128.100/dab/docs/portaldab/publicacoes/guia_alimentar_populacao_ brasileira.pdf>. Acesso em: 18 abr. 2015.

CANESQUI, A. M. Comida de rico, comida de pobre: um estudo sobre alimentaçáo num bairro popular. 267f. Tese (Doutorado em Medicina) - Faculdade de Ciências Médicas, Universidade Estadual de Campinas, Campinas, 1976.

. Pesquisas qualitativas em nutrição e alimentação. Revista de Nutrição, v. 22, n. 1, p. 125-139, 2009. 
CARVALHO, M. C. V. S. Práticas e saberes na alimentação: natural, racional ou social? In:

LUZ, M.T.; BARROS, N.F. Racionalidades médicas e práticas integrativas em saúde, estudos teóricos e empíricos. Rio de Janeiro: CEPESC-IMS-UERJ-ABRASCO, 2012, p. 425-442.

CARVALHO, M. C. V. S.; LUZ, M. T; PRADO, S. D. Comer, alimentar e nutrir: categorias analíticas instrumentais no campo da pesquisa científica. Revista Ciência \& Saúde Coletiva, v. 16, n. 1, p. 155-163, 2011.

DELEUZE, G. Diferença e repetição. 2. ed. Rio de Janeiro: Graal, 2006.

DILTHEY, W. Introducción a Ias Ciencias del Espíritu. Madrid: Ed. Revista de Occidente, 1956.

DURKHEIM, E. A evolução pedagógica. Porto Alegre: Artes Médicas, 1995.

ELIAS, N. O Processo Civilizador: uma história dos costumes. Trad. Ruy Jungmann. Rio de Janeiro: Jorge Zahar Editor, 1990, v. 1.

FISCHLER, C. El (H)omnivoro. El gusto, la cocina y el cuerpo. Barcelona: Anagrama, 1995.

FREITAS, M. C. S. et al. Hábitos alimentares e os sentidos do comer. In: DIEZ-GARCIA, R. W.; CERVATO-MANCUSO, A. M. Mudanças alimentares e educação nutricional. Rio de Janeiro: Guanabara Koogan, 2011, p. 35-42.

GIDDENS, A. Modernidade e identidade. Rio de Janeiro: Jorge Zahar, 2002.

GOÉS, J.A.W. Hábitos alimentares: globalização ou diversidade? In: FREITAS, M. C. S.; FONTES, G. A. V.; OLIVEIRA, N. (Org.). Escritas e Narrativas sobre Alimentaçâo e Cultura. Salvador: EDUFBA, 2008, p. 375-404.

GRACIA-ARNAIZ, M. Comemos lo que somos: Reflexiones sobre cuerpo, género y salud. Barcelona: Icaria Editorial, 2015.

GUALANDI, A. Deleuze. São Paulo: Estação Liberdade, 2003.

KLOTZ-SILVA, J. Alimentação e cultura como campo científico no Brasil. 2011. $184 \mathrm{f}$. Dissertação (Mestrado em Alimentação, Nutrição e Saúde) - Instituto de Nutrição, Universidade do Estado do Rio de Janeiro, Rio de Janeiro, 2011.

KLOTZ-SILVA, J. et al. Alimentação e cultura como campo científico no Brasil. Physis, v. 20, n. 2, p. 413-442, 2010.

KLOTZ-SILVA, J.; PRADO, S. D.; SEIXAS, C. M. Comportamento alimentar no campo da Alimentação e Nutrição: do que estamos falando? Physis, v. 26, n. 4, p. 1.103-1.123, 2016. MAUSS, M. Sociologia e antropologia. São Paulo: EPU \& Edusp, 1974.

MINAYO, M. C. S. Conceitos para operacionalização da pesquisa. In:_____. O desafio do conhecimento: pesquisa qualitativa em saúde. 12. ed. Sáo Paulo: Hucitec, 2010, p. 175-181. MORA, J. F. Dicionário de Filosofia. Lisboa: Publicaçôes Dom Quixote, 1978.

MORIN, E. Introdução ao Pensamento Complexo. 4. ed. Porto Alegre: Sulina, 2011.

ORTIZ, R. (Org.). Pierre Bourdieu: sociologia. Trad. Paula Monteiro e Alicia Auzmendi. São Paulo: Ática, 1983. (Coleção grandes cientistas sociais; n. 39). 
PACHECO, S. S. M. O hábito alimentar enquanto um comportamento culturalmente produzido. In: FREITAS, M. C. S.; FONTES, G. A. V.; OLIVEIRA, N. (Org.). Escritas e Narrativas sobre Alimentação e Cultura. Salvador: EDUFBA, 2008, p. 217-238.

PAIVA, J. B. Hábitos alimentares regionais no âmbito do Programa Nacional de Alimentação Escolar em um município do sertão baiano: uma abordagem qualitativa. 2011. $132 \mathrm{f}$. Dissertação (Mestrado em Alimentos, Nutrição e Saúde) - Escola de Nutrição, Universidade Federal da Bahia, Salvador, 2011.

PAIVA, J. B.; FREITAS, M. C. S.; SANTOS, L. A. S. Hábitos alimentares regionais no Programa Nacional de Alimentação Escolar: um estudo qualitativo em um município do sertão da Bahia, Brasil. Revista de Nutrição, v. 25, n. 2, p. 191-202, 2012.

PRADO, S. D. et al. Alimentação e Nutrição como campo científico autônomo no Brasil: conceitos, domínios e projetos políticos. Revista de Nutrição. Campinas, v. 24, n. 6, p. 927937, 2011.

SETTON, M. G. J. A teoria do habitus em Pierre Bourdieu: uma leitura contemporânea. Revista Brasileira de Educação, n. 20, p. 60-70, 2002.

. Teoria disposicionalista e habitus alimentar: elementos de orientação para análises acerca da incorporação de disposiçóes culturais. In: SILVA, F. C. T; PEREIRA, M. V. M. Observatório de cultura escolar: estudos e pesquisas sobre escola, currículo e cultura escolar. Campo Grande: Editora UFMS, 2013, p. 119-144.

SILVA, M. S. et al. Risco de doenças crônicas não transmissíveis na população atendida em Programa de Educação Nutricional em Goiânia (GO), Brasil. Ciência \& Saúde Coletiva, v. 19, n. 5, p. 1.409-1.418, 2014.

VASCONCELOS, F. A. G. Tendências históricas dos estudos dietéticos no Brasil. História, Ciências, Saúde-Manguinhos, v. 14, n. 1, p. 197-219, 2007.

VAZ, D. S. S.; BENNEMANN, R. M. Comportamento alimentar e hábito alimentar: uma revisão. Revista UNINGÁ Review, v. 20, n. 1, p. 108-112, 2014.

WACQUANT, L. Esclarecer o Habitus. Educação \& Linguagem, ano 10, n. 16, p. 63-71, 2007. WEBER, M. A ética protestante e o espirito do capitalismo. São Paulo: Pioneira, 1967.

\section{Notas}

${ }^{1}$ Este texto deriva da tese de doutorado de Juliana Klotz-Silva, desenvolvida no Programa de Pós-Graduação em Alimentação, Nutrição e Saúde do Instituto de Nutrição, Universidade do Estado do Rio de Janeiro. Agradecemos o apoio financeiro da CAPES, através de bolsa de doutorado, do CNPq, da FAPERJ e do Programa Prociência-UERJ.

${ }^{2}$ J. Klotz-Silva contribuiu na concepção do estudo, redação e revisão final. S. D. Prado contribuiu com a orientaçáo do estudo, redação, revisão e aprovação final. C. M. Seixas contribuiu com a redação, revisão e aprovação da versão final. 
The power of "food habit": conceptual references to the field of Food and Nutrition

On this essay, we seek to discuss how the category food habit has been used in the Food and Nutrition field when it comes to propose solutions to health grievances associated with food practices. The effort to examine the idea of food habit is related to the intention of indicating its (re)connections to other science fields. In the Food and Nutrition field, eating habits mostly relates to what one eats regularly. As an empirical category, devoid of concepting or questioning epistemological issues, it is used as common knowledge phrase in academia, naturalized, studied through characteristic methods of Simple Thought, explained by Edgar Morin, and for which there are no substantial questioning concerning its meanings in cultural, social and psychical context. Among many possibilities yet to be explored, it is indicated to follow on with Pierre Bourdieu through the concept habitus, as suggested by some authors and done also by others as one of the paths that can enrich analyzes. It is considered that when operating with concepts that allow taking into account the complexity (as conceived by Morin) that embodies eating habits, the Food and Nutrition field itself can keep on more energized and more autonomy in its scientific read.

> Keywords: food; eating habits; habitus; complexity. 